\title{
Preparation and characterization of EPDM/silica nanocomposites prepared through non-hydrolytic sol-gel method in the absence and presence of a coupling agent
}

\author{
T. H. Mokhothu', A. S. Luyt ${ }^{1 *}$, M. Messori ${ }^{2}$ \\ ${ }^{1}$ Department of Chemistry, University of the Free State (Qwaqwa Campus), Private Bag X13, 9866 Phuthaditjhaba, South \\ Africa \\ ${ }^{2}$ Department of Engineering 'Enzo Ferrari', University of Modena and Reggio Emilia, Via Vignolese 905/A - 41125 \\ Modena, Italy
}

Received 21 March 2014; accepted in revised form 4 June 2014

\begin{abstract}
Ethylene propylene diene monomer (EPDM) rubber composites containing in situ generated silica particles was prepared through a non-hydrolytic sol-gel (NHSG) method with silicon tetrachloride as precursor. The silica particles were homogenously dispersed in the EPDM matrix, but there were agglomerates at high silica contents. The swelling experiments showed a decrease in the crosslinking density of the vulcanized rubber due to the presence of the silica particles for both the composites prepared in the presence and absence of a coupling agent, bis-[-3-(triethoxysilyl)-propyl]-tetrasulfide (TESPT). Unlike the composites prepared through a hydrolytic sol-gel (HSG) method with TEOS as precursor, the TESPT did not seem to take part in the sol-gel reaction. The presence of TESPT influenced the interaction and dispersion of the silica particles in the EPDM matrix, which gave rise to increased thermal stability of the EPDM when compared to the composites prepared in the absence of TESPT. However, ethylene chloride and TESPT evaporated from the samples at temperatures below the EPDM decomposition range. The values of the Nielsen model parameters, that gave rise to a good agreement with the experimentally determined Young's modulus values, indicated improved dispersion and reduced size of the silica aggregates in the EPDM matrix. There was also good agreement between the storage modulus and Young's modulus values. The filler effectiveness (Factor C) indicated a mechanical stiffening effect and a thermal stability contribution by the filler, while the damping reduction (DR) values confirmed that the EPDM interacted strongly with the well dispersed silica particles and the polymer chain mobility was restricted. The tensile properties, however, were in some cases worse than those for the samples prepared through the HSG method in the presence of TEOS.
\end{abstract}

Keywords: polymer composites, EPDM, silica, non-hydrolytic sol-gel

\section{Introduction}

The incorporation of inorganic oxides such as silica and/or titania into rubber matrices prepared by the conventional sol-gel routes led to materials with enhanced properties when compared to both unfilled rubbers and rubbers filled with traditionally prepared particles. The sol-gel process is a chemical technique initially employed to prepare high purity inorganic oxides such as glasses and ceramic mate- rials. The advantage of the sol-gel route is that it allows fine control of particle size and distribution owing to the low temperature conditions, and it is therefore suitable for organic materials to be introduced into the process. The most widely used solgel route is the hydrolytic process, which involves hydrolysis and condensation of the precursors (metal oxide) to form oxide networks. The hydrolytic sol-gel process is generally divided into two steps:

\footnotetext{
*Corresponding author, e-mail: LuytAS@qwa.ufs.ac.za

(c) BME-PT
} 
the first step hydrolysis, which produces hydroxyl groups, and the second step condensation, which involves the polycondensation of hydroxyl groups and residual alkoxyl groups to form a three-dimensional network. The inorganic oxide can be directly grown in the organic matrix leading to the formation of organic-inorganic hybrid structures composed of metal oxide and organic phases intimately mixed with each other. The main drawback of the hydrolytic route is the low miscibility of the sol-gel aqueous system, which limits the dispersion of the filler in the polymer [1-3]. The inorganic oxide prepared in the hydrolytic sol-gel way also has low purity and crystallinity.

An alternative method to prepare organic-inorganic material is the non-hydrolytic sol-gel (NHSG) process, which can be used to produce metal oxides of high purity and crystallinity. Moreover, the NHSG route features different reactions and reaction conditions, which significantly affect the texture, homogeneity and surface chemistry of the resulting oxide [4-6]. In the past 20 years, several non-hydrolytic synthesis methods of oxides and mixed oxides have been described, involving the reaction of precursors (alkoxides, chlorides, acetylacetonates) with oxygen donors (ethers, alcohols, ketones) [4-10]. The main non-hydrolytic routes involve the reaction of a metal chloride with either a metal alkoxide or organic ether, acting as oxygen donors [7-9] as described in Figure 1.

On the other hand, the formation of alkyl halide and/or alkyl ethers as by-products and the potential incompatibility with oxygen containing species have to be taken into account as possible negative aspects. The possibility of preparing polymers reinforced with metal oxides generated in situ by a nonhydrolytic sol-gel process, has been reviewed by several authors in recent publications $[2,3]$. The authors focused on poly(methyl methacrylate) (PMMA)/titanium dioxide $\left(\mathrm{TiO}_{2}\right)$ and epoxy resin/ titanium dioxide $\left(\mathrm{TiO}_{2}\right)$ nanocomposites. In both investigations benzyl alcohol (BzOH) was used as an oxygen donor and titanium(IV)chloride $\left(\mathrm{TiCl}_{4}\right)$ as

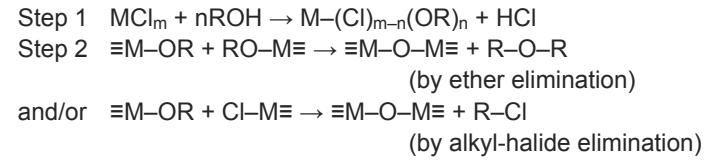

Figure 1. Non-hydrolytic sol-gel reaction scheme a precursor. In both cases, improvements in the mechanical and functional properties were observed, independent of the chosen polymer matrix. This was due to the improved interfacial interactions between the organic and inorganic phases brought about by the non-hydrolytic sol-gel route. Morselli et al. [1] investigated the non-hydrolytic sol-gel synthesis of $\mathrm{PMMA} / \mathrm{TiO}_{2}$ nanocomposites, starting from titanium(IV)chloride as a titania $\left(\mathrm{TiO}_{2}\right)$ precursor and benzyl alcohol as an oxygen donor. The in situ generated titania did not have any negative effect on the PMMA molecular weight and thermal stability, and a significant increase in both the glass transition temperature and the storage modulus was observed for all the PMMA nanocomposites.

However, the use of the NHSG processes to prepare filled polymers is not widely reported in literature, and most reports are limited to rigid thermoplastics $[1,2]$ and thermosets [3]. In the present work silica nano-particles were in situ generated by using an NHSG process from silicon tetrachloride $\left(\mathrm{SiCl}_{4}\right)$ as silica precursor and tert-butanol $(t-\mathrm{BuOH})$ as oxygen donor in the presence of EPDM rubber dissolved in toluene. The low boiling point of $t-\mathrm{BuOH}$ allows the use of mild conditions during solvent elimination, in which polymer chain degradation and/or plasticizing effects can be avoided for the composites prepared by the sol-gel reaction. Moreover, the $t-\mathrm{BuOH}$ is not only used as an oxygen donor, but due to the alkyl group steric effect, it can also act as a capping agent, and therefore, as a particle size and phase controller. This approach is expected to reduce the filler-filler interaction and give rise to improved thermal, mechanical and thermomechanical properties, as well as a better morphology and improved crosslinking.

\section{Experimental}

\subsection{Materials}

Silicon tetrachloride (SiCl4), tert-butanol $(t-\mathrm{BuOH})$, tin(II)2-ethylhexanoate, dicumyl peroxide, bis-[-3(triethoxysilyl)-propyl]-tetrasulfide (TESPT) and toluene were all supplied by Sigma-Aldrich (Milan, Italy). The materials were used as received without further purification. Ethylene propylene diene monomer rubber (EPDM), Polimeri Europa Dutral ${ }^{\circledR}$ TER 4038, density $0.91 \mathrm{~g} \cdot \mathrm{cm}^{-3}$, was provided by ATG Italy (Castel d'Argile, BO, Italy). 


\subsection{Preparation of EPDM/SiO nanocomposites in the absence and presence of TESPT}

The EPDM/ $/ \mathrm{SiO}_{2}$ nanocomposites were prepared by dissolving EPDM rubber in toluene $(3 \mathrm{~g} / 100 \mathrm{~mL})$ at room temperature, and a coupling agent (TESPT) was added ( $4 \mathrm{wt} \%$ with respect to EPDM) to the EPDM solution for composites prepared in the presence of TESPT. The non-hydrolytic sol-gel (NHSG) system was prepared as follows: a given amount of $\mathrm{SiCl}_{4}$ was added drop-wise to $t$ - $\mathrm{BuOH}$ under vigorous stirring at room temperature for 15 minutes, followed by addition of tin(II)2-ethylhexanoate (1:25:0.04 mol ratio). The resulting sol was mixed with a previously prepared EPDM and EPDMTESPT solutions in round-bottom flasks and heated in an oil bath at $70^{\circ} \mathrm{C}$ for 24 hours in order to complete the NHSG reaction for the conversion of $\mathrm{SiCl}_{4}$ to $\mathrm{SiO}_{2}$. The solutions were cooled to room temperature, followed by the addition of dicumyl peroxide (DCP) (4 wt \% with respect to EPDM) under stirring. The reaction mixtures were taken to a rotating evaporator to eliminate about $90 \%$ of the volatile substances (toluene, unreacted $t-\mathrm{BuOH}$ and byproducts of the NHSG reaction). The samples with and without TESPT $\left(90 / 10 \mathrm{w} / \mathrm{w}\right.$ EPDM $/ \mathrm{SiO}_{2}$ and 80/20 w/w EPDM/ $/ \mathrm{SiO}_{2}$ ) were obtained by casting the solutions in Petri dishes, dried overnight and later vulcanized by compression at $160^{\circ} \mathrm{C}$ for $20 \mathrm{~min}$. The same route was used to prepare TESPT containing EPDM samples as a control for FTIR analysis. In this case no other chemical was added.

\subsection{Characterization methods}

The transmission electron microscopy (TEM) images were obtained using a $200 \mathrm{kV}$ FEI Tecnai20 transmission electron microscope fitted with Gatan Tridiem. The EPDM silica filled samples were mounted on cryo-pins and frozen in liquid nitrogen. 100$150 \mathrm{~nm}$ sections were cut at $-100^{\circ} \mathrm{C}$ using a Reichert Ultra-Cut $\mathrm{S}$ ultra-microtome chuck, collected on copper grids and viewed.

Fourier-transform infrared (FTIR) spectra of the pure EPDM and its silica filled nanocomposites were obtained using a Perkin Elmer Spectrum 100 FTIR spectrophotometer. The samples were analyzed over a range of $600-4000 \mathrm{~cm}^{-1}$ with a resolution of $4 \mathrm{~cm}^{-1}$ using an attenuated total reflectance (ATR) detector. All the spectra were averaged over 16 scans.
The crosslinking degree was determined through equilibrium swelling tests by immersing at least three rectangular specimens for each composition in $15 \mathrm{~mL}$ of toluene at room temperature for several hours, and the mean values are reported. The solvent was replaced hourly after each measurement to eliminate all uncross-linked fractions, such as unvulcanized EPDM chains, which could lead to incorrect values of the swelling ratio. The swelling experiments were done over a period of 24 hours until a constant mass was reached. Equilibrium swelling was determined until the swollen mass $\left(m_{\mathrm{s}}\right)$ reached a constant value, after which the samples were dried to constant mass (dried mass $\left(m_{\mathrm{d}}\right)$ ) and the absolute swelling ratio $(q)$ was evaluated according to Equation (1):

$q=\frac{m_{\mathrm{s}}}{m_{\mathrm{d}}}$

The absolute extractable fraction $(f)$, where $m_{0}$ is the mass of the sample before immersion in toluene, was determined using Equation (2):

$f=\frac{m_{0}-m_{\mathrm{d}}}{m_{0}} \cdot 100$

The values of $q$ and $f$ were both normalised to the actual EPDM weight. Their values were determined using Equations (3) and (4):

$q_{\mathrm{EPDM}}=\frac{q}{c_{\mathrm{EPDM}}}$

$f_{\mathrm{EPDM}}=\frac{f}{c_{\mathrm{EPDM}}}$

where $c_{\text {EPDM }}$ is the mass fraction of EPDM present in the composites. The gel content was determined using Equations (5) to (7), where $m_{\text {EPDM }}$ is the mass of EPDM without silica.

$m_{\mathrm{EPDM}}=m_{0} \cdot c_{\mathrm{EPDM}}$

$\%$ Extraction $=\frac{m_{0}-m_{\mathrm{d}}}{m_{\mathrm{EPDM}}} \cdot 100$

$\% \mathrm{Gel}=100-\%$ Extraction

Thermogravimetric analysis (TGA) was performed with a Perkin Elmer STA6000 simultaneous thermal analyzer. The analysis was done under flowing nitrogen at a constant flow rate of $20 \mathrm{~mL} \cdot \mathrm{min}^{-1}$, and the samples $(20-25 \mathrm{mg})$ were heated from 25 to $600^{\circ} \mathrm{C}$ at a heating rate of $10^{\circ} \mathrm{C} \cdot \mathrm{min}^{-1}$. 
The TGA-FTIR analyses were performed in a Perkin Elmer STA6000 simultaneous thermal analyser from Waltham, Massachusetts, U.S.A. The analyses were done under flowing nitrogen at a constant flow rate of $20 \mathrm{~mL} \cdot \mathrm{min}^{-1}$. Samples $(20-25 \mathrm{mg})$ were heated from 30 to $600^{\circ} \mathrm{C}$ at $10^{\circ} \mathrm{C} \cdot \mathrm{min}^{-1}$. The furnace was linked to the FTIR (Perkin Elmer Spectrum 100) with a gas transfer line. The volatiles were scanned over a $400-4000 \mathrm{~cm}^{-1}$ wavenumber range at a resolution of $4 \mathrm{~cm}^{-1}$. The FTIR spectra were recorded in the transmittance mode at $250^{\circ} \mathrm{C}$ during the thermal degradation process.

The tensile properties of the samples were determined using a Hounsfield H5KS tensile tester at a crosshead speed of $100 \mathrm{~mm} \cdot \mathrm{min}^{-1}$ and $20 \mathrm{~mm}$ gauge length at ambient temperature. The samples were rectangular shaped with a width of $12 \mathrm{~mm}$ and a thickness varying between 0.47 and $0.67 \mathrm{~mm}$. At least five specimens were tested for each composition, and the mean values are reported. For comparison, Young's modulus was predicted according to Nielsen's theoretical model [11-17].

The dynamic mechanical analysis (DMA) of the samples was done in a Perkin Elmer Diamond DMA dynamic mechanical analyzer. Rectangular shaped samples with dimensions of $40 \mathrm{~mm}$ length, $10 \mathrm{~mm}$ width and thickness varying between 0.47 and $0.67 \mathrm{~mm}$ thick were tested in the tensile mode, while heated under nitrogen flow from -100 to $100^{\circ} \mathrm{C}$ at a heating rate of $3^{\circ} \mathrm{C} \cdot \mathrm{min}^{-1}$, and at a frequency of $1 \mathrm{~Hz}$.

\section{Results and discussion}

The TEM micrographs and the particle size distribution graphs (determined from an average of 40 particles per sample) of the EPDM/silica composites prepared in the absence and presence of TESPT are shown in Figures 2 and 3. The 90/10 w/w EPDM/ $\mathrm{SiO}_{2}$ composite prepared in the absence of TESPT shows homogeneously and fairly well dispersed silica particles, but with clear evidence of particle agglomeration. Much larger agglomerates are visible for the $80 / 20 \mathrm{w} / \mathrm{w} \mathrm{EPDM} / \mathrm{SiO}_{2}$ sample prepared in the absence of TESPT, indicating increased particle-particle interaction (Figure 2b). The particle size distribution determined from the visible particles confirms the presence of larger particles for the composites prepared without TESPT (Figure 3a). The introduction of TESPT during synthesis reduced the particle-particle interaction, giving rise to reduced particle agglomeration and observably better dis- persion (Figures 2c and 2d, and Figure 3b). Well dispersed and non-agglomerated particles are even visible in the $80 / 20 \mathrm{w} / \mathrm{w} \mathrm{EPDM} / \mathrm{SiO}_{2}$ sample (Figure 2d). In our case the in situ synthesis using the non-hydrolytic route seems to have overcome the problems we experienced by using the hydrolytic route, in which the low miscibility of the sol-gel aqueous system gave rise to more agglomeration and reduced dispersion of the silica particles [1-4]. The larger agglomerates at higher silica contents is the result of an increase in coalescence of the growing silica particles when increasing the amount of in situ formed dispersed phase. The silica particles may also have agglomerated in the suspension, because the hydrophilic silica particles have a tendency to associate via hydrogen bonding [16-20]. When comparing the particle size distribution results with those obtained during our previous study on the same system, but with the samples prepared by an HSG method in the absence and presence of a coupling agent $[16,17]$, smaller particles were observed in the present study. This confirms that the NHSG route was able to produce smaller filler particles in the rubber matrix than the HSG route.

The FTIR spectra of all the investigated samples are shown in Figure 5. In the nanocomposites the EPDM can be identified by two strong peaks around 2920 and $2850 \mathrm{~cm}^{-1}$ assigned to the $\mathrm{C}-\mathrm{H}$ stretching vibrations (Figure 5a). More peaks are observed at 721, 1376 and $1464 \mathrm{~cm}^{-1}$ and are assigned to $\mathrm{CH}_{2}$ stretching, and $\mathrm{CH}_{3}$ and $\mathrm{CH}_{2}$ bending respectively $[16,17]$. The $\mathrm{SiO}_{2}$ in the nanocomposites can be identified from strong stretching vibrations of the siloxane ( $\mathrm{Si}-\mathrm{O}-\mathrm{Si}$ ) bond at $1085 \mathrm{~cm}^{-1}$, a small asymmetric stretch peak of $\mathrm{Si}-\mathrm{O}-\mathrm{C}$ at $802 \mathrm{~cm}^{-1}$, and a small peak at $938 \mathrm{~cm}^{-1}$ assigned to $\mathrm{Si}-\mathrm{O}$ stretching, indicating the presence of some silanol ( $\mathrm{Si}-\mathrm{OH})$ groups, which was confirmed by comparing the FTIR spectrum of $\mathrm{SiO}_{2}$ in Figure 5a with those of the nanocomposites. The broad peak at $3340 \mathrm{~cm}^{-1}$ in the $\mathrm{SiO}_{2}$ spectrum could be assigned to the stretching vibrations of $-\mathrm{OH}$ groups as a result of unreacted silanols (-Si-OH). Similar peaks are observed for the EPDM/ $\mathrm{SiO}_{2}$ composites, but without the $-\mathrm{OH}$ peak (Figure 5a). We observed and explained the same peaks in our previous study on the hydrolytic sol-gel (HSG) synthesis at long reaction times [16], and the peaks were the result of grafted and/or unreacted fractions of TEOS such as the ethoxysilane $\left(-\mathrm{Si}-\mathrm{OC}_{2} \mathrm{H}_{5}\right)$ and silanol groups $(-\mathrm{Si}-\mathrm{OH})$ due to unhydrolyzed silica 

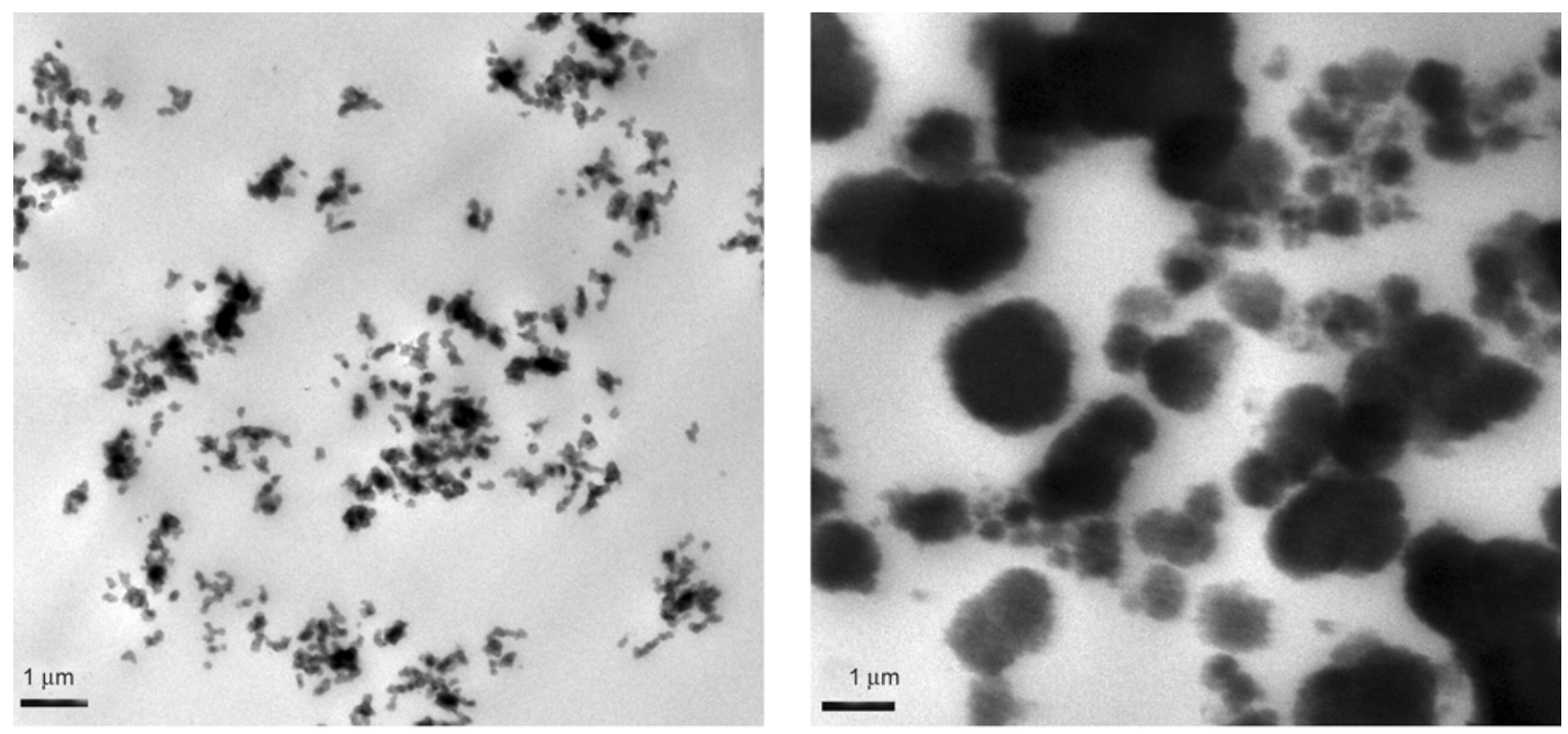

a)

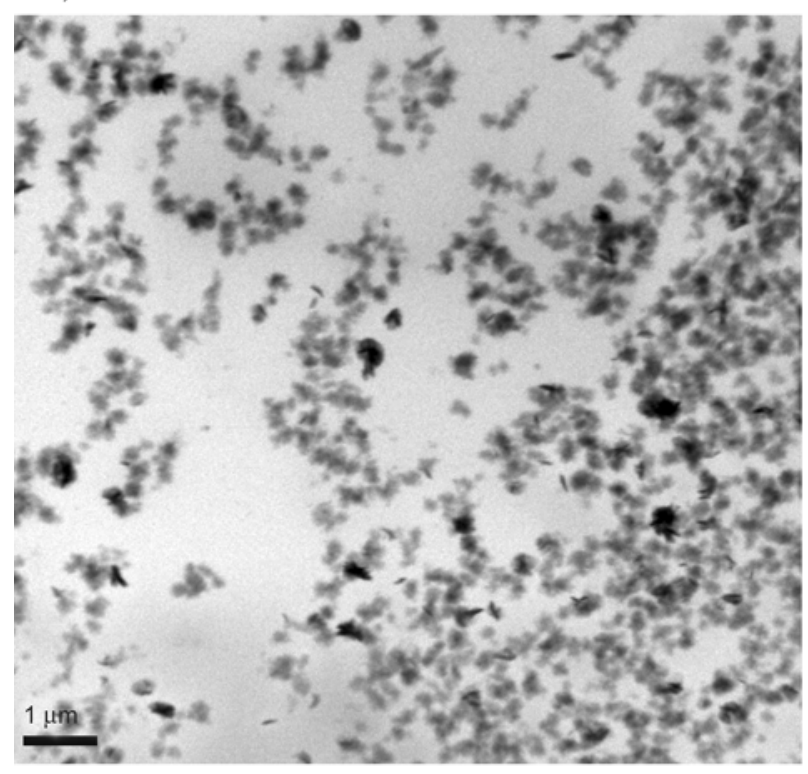

c)

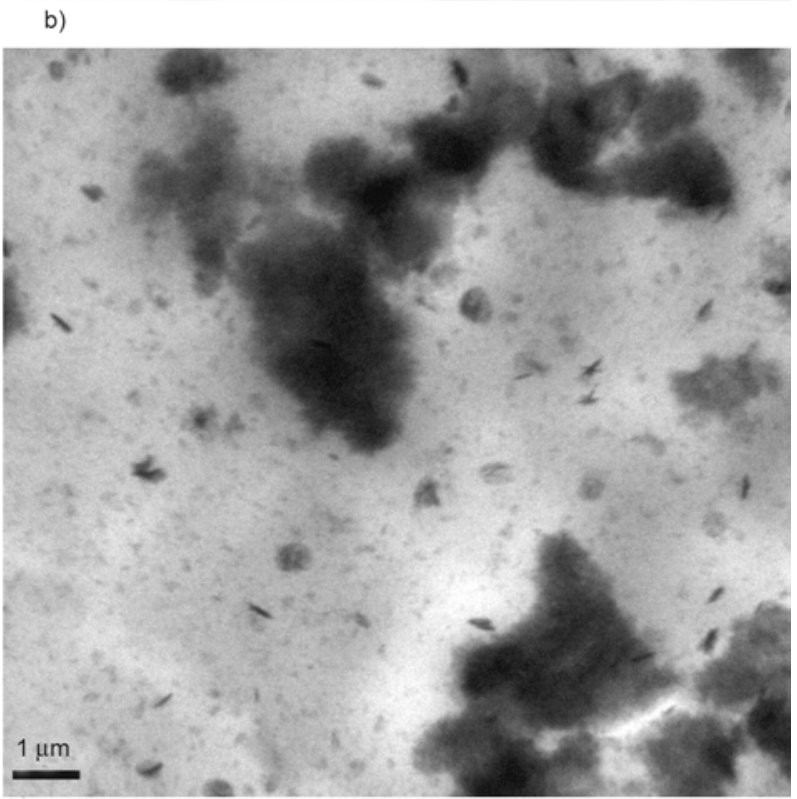

d)

Figure 2. TEM micrographs of composites without TESPT (a) 90/10 w/w and (b) 80/20 w/w EPDM/SiO 2 , and with TESPT (c) $90 / 10 \mathrm{w} / \mathrm{w}$ and (d) $80 / 20 \mathrm{w} / \mathrm{w} \mathrm{EPDM} / \mathrm{SiO}_{2}$
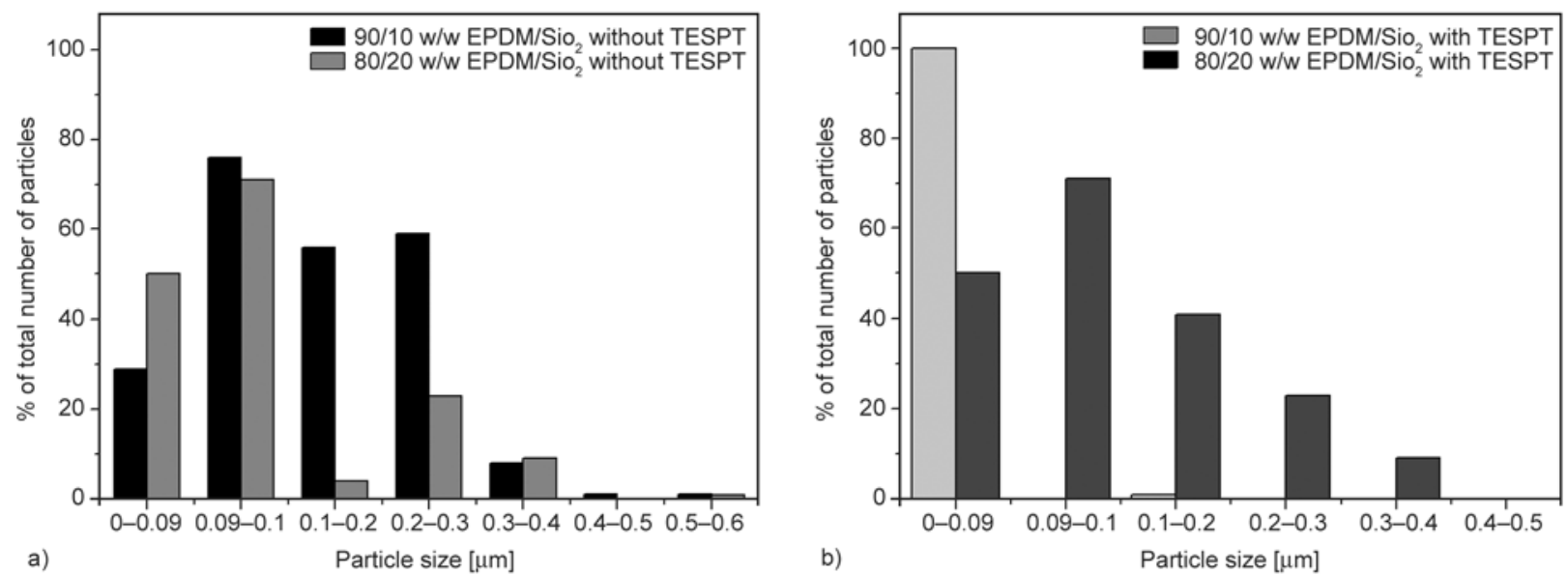

Figure 3. Particle size distribution graphs of $\mathrm{EPDM} / \mathrm{SiO}_{2}$ composites prepared in the (a) absence and (b) presence of TESPT 
that reacted with dicumyl peroxide (DCP) during vulcanization. The NHSG process is divided into two steps. The first step involves the reaction of a metal halide or a metal alkoxide with an organic oxygen donor (such as an alcohol or ether). The second step (condensation) can follow different pathways depending on the alkoxide used. One of the most used condensation reactions occurs through alkyl halide elimination and/or ether elimination as indicated in Figure 1 [1, 5, 6, 21-23]. However, tertiary alcohols can lead to the in situ formation of hydroxyl groups, which react in a second step with a chloride group according to Figure 4. The alcohol route has been much less investigated for the preparation of oxides and mixed oxides than the alkoxide and ether routes [5].

In this study a tertiary alcohol $(t-\mathrm{BuOH})$ was used and according to Figure 4, the alcohol has reacted further to form silanol groups and this could explain the presence of the small peak at $938 \mathrm{~cm}^{-1}$ in the nanocomposite spectra, which is the result of silanol groups that did not react further to form siloxane groups ( $\mathrm{Si}-\mathrm{O}-\mathrm{Si}$ ), and that may have grafted to the rubber chains by reacting with the DCP during vulcanization (Figure 5a).

The spectrum of EPDM-TESPT in Figure 5b contains a combination of the peaks observed for EPDM in Figure 5a and TESPT in Figure 5b with no new peaks or obvious peak shifts. TESPT therefore clearly did not react with EPDM under the

Step $1 \quad \mathrm{M}-\mathrm{Cl}+\mathrm{ROH} \rightarrow \mathrm{M}-\mathrm{OH}+\mathrm{R}-\mathrm{Cl}$

Step $2 \quad \mathrm{M}-\mathrm{Cl}+\mathrm{M}-\mathrm{OH} \rightarrow \mathrm{M}-\mathrm{O}-\mathrm{M}+\mathrm{H}-\mathrm{Cl}$

Figure 4. In situ formation of hydroxyl groups during the non-hydrolytic sol-gel process

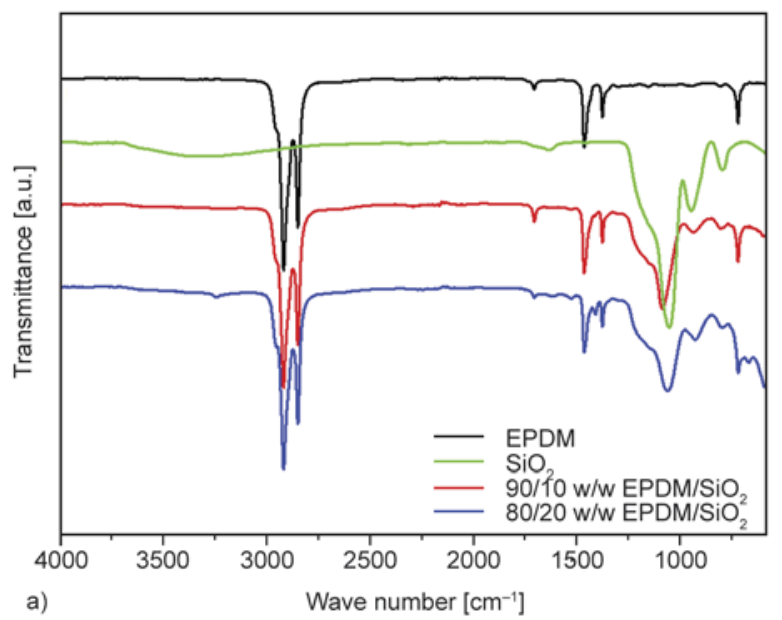

preparation conditions used. The FTIR spectrum of the $80 / 20 \mathrm{w} / \mathrm{w} \mathrm{EPDM} / \mathrm{SiO}_{2}$ prepared in the presence of TESPT shows that most of the silanols ( $\mathrm{Si}-\mathrm{OH})$ reacted to form $\mathrm{Si}-\mathrm{O}-\mathrm{Si}$ bonds, with the accompanying reduction in the number of free $-\mathrm{OH}$ groups. This means that the silanols completely reacted to form silica links (Figure 5b). This spectrum also shows peaks around 1390, 1167 and $780 \mathrm{~cm}^{-1}$, that were the characteristic peaks observed for TESPT in Figure 5b. Unlike the composites prepared through the hydrolytic sol-gel (HSG) route with TEOS as precursor [17], the TESPT did not seem to take part in the sol-gel reaction, and probably accumulated at the EPDM-silica interface.

The equilibrium swelling and gel content results for the $\mathrm{EPDM} / \mathrm{SiO}_{2}$ composites with and without TESPT are shown in Table 1. The equilibrium swelling test shows a decrease in the crosslink density with increasing filler content of the EPDM/ $\mathrm{SiO}_{2}$ composites with and without TESPT. This can be observed from the absolute swelling ratio ( $q$ and $q_{\text {EPDM }}$ ) values that increase with increasing silica content, the increasing values of the extractable fraction $(f$ and $f_{\text {EPDM }}$ ), and the decreasing gel content values. The presence of the NHSG in situ generated silica particles in the EPDM inhibited the crosslinking of the rubber chains during vulcanization. The reason for this observation is that increasing amounts of DCP were used for the grafting of silanol onto the rubber chains and therefore less DCP was available to initiate the crosslinking of the rubber chains. The FTIR results also confirm this explanation, especially for composites without TESPT (10 and $20 \mathrm{w} / \mathrm{w}$ EPDM/ $\mathrm{SiO}_{2}$ ). From the swelling and extraction results it is

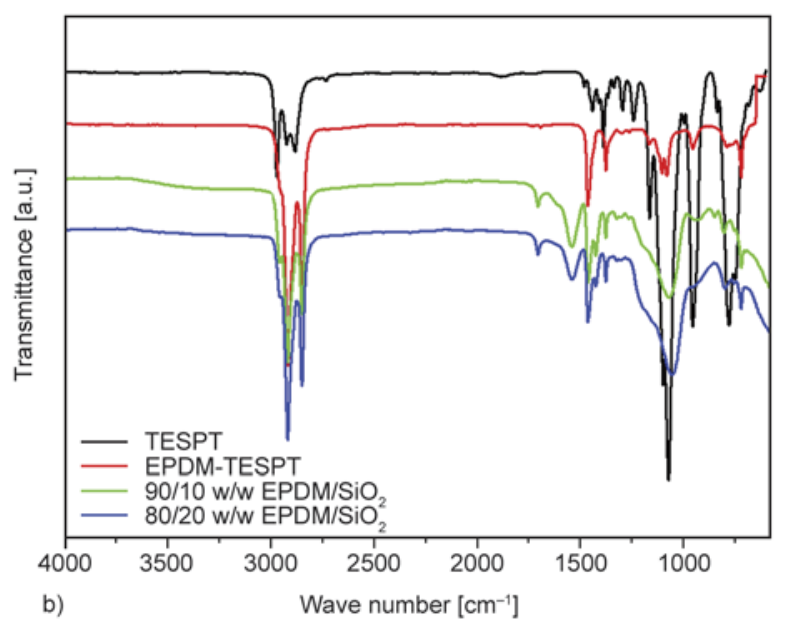

Figure 5. FTIR spectra of (a) EPDM, $\mathrm{SiO}_{2}$ and the EPDM/SiO 2 composites, and (b) TESPT, EPDM-TESPT, and $\mathrm{EPDM} / \mathrm{SiO}_{2}$ with TESPT composites 
Table 1. Swelling and extraction results of EPDM and the $\mathrm{EPDM} / \mathrm{SiO}_{2}$ composites

\begin{tabular}{|c|c|c|c|c|c|}
\hline $\begin{array}{c}\text { Samples } \\
(w / w)\end{array}$ & $\mathbf{Q}$ & qEPDM & $\begin{array}{c}\mathbf{f} \\
{[\%]}\end{array}$ & $\begin{array}{c}f_{\text {EPDM }} \\
{[\%]}\end{array}$ & $\begin{array}{l}\text { Gel } \\
{[\%]}\end{array}$ \\
\hline EPDM & $2.7 \pm 0.0$ & $2.7 \pm 0.0$ & $4.2 \pm 5.5$ & $4.2 \pm 5.5$ & $95.8 \pm 5.5$ \\
\hline \multicolumn{6}{|c|}{ Composites without TESPT } \\
\hline 90/10 EPDM/SiO ${ }_{2}$ & $3.1 \pm 0.1$ & $3.4 \pm 0.1$ & $7.9 \pm 0.5$ & $8.7 \pm 0.5$ & $91.2 \pm 0.5$ \\
\hline $80 / 20 \mathrm{EPDM} / \mathrm{SiO}_{2}$ & $6.5 \pm 0.0$ & $7.7 \pm 0.0$ & $13.1 \pm 1.3$ & $15.4 \pm 1.5$ & $83.7 \pm 1.6$ \\
\hline \multicolumn{6}{|c|}{ Composites with TESPT } \\
\hline 90/10 EPDM/ $/ \mathrm{SiO}_{2}$ & $3.2 \pm 0.0$ & $3.5 \pm 0.1$ & $7.8 \pm 0.8$ & $8.6 \pm 0.9$ & $91.3 \pm 0.9$ \\
\hline $80 / 20 \mathrm{EPDM} / \mathrm{SiO}_{2}$ & $2.7 \pm 0.0$ & $3.1 \pm 0.0$ & $9.8 \pm 0.4$ & $11.5 \pm 0.5$ & $87.8 \pm 0.5$ \\
\hline
\end{tabular}

clear that the in situ generation of silica particles through the sol-gel process led to a hindering effect on the vulcanization process, which limited the extent of crosslinking of the EPDM phase, as already observed and explained for the same material prepared through HSG synthesis with TEOS precursor at long reaction times [16].

In the case of the composites prepared in the presence of TESPT the decrease in the crosslinking density is probably not the result of DCP reacting with the silanol groups, because the FTIR analysis of these composites does not show the presence of silanol groups, indicating that most of the $\mathrm{Si}-\mathrm{OH}$ reacted to form siloxane groups. Another possible explanation is that there was enough free volume between the chains to accommodate the toluene molecules during the swelling test, which led to an increase in the swelling ratios. A similar observation and explanation were given for HSG composites prepared from TEOS in the presence of TESPT at long reaction times [17].

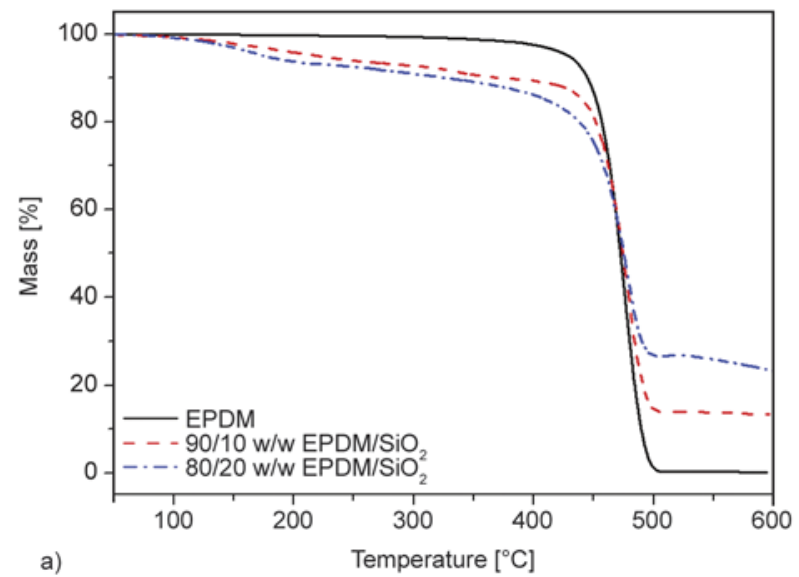

The TGA curves of all the investigated samples are shown in Figure 6, while Table 2 shows a summary of the TGA results. The TGA curves show two mass loss steps for all the composites. This is different from the TGA results for the same composites prepared according to the HSG route [16]. These samples did not show the first mass loss step observed here. In order to figure out the reasons for this difference, we did a TGA-FTIR analysis on the samples prepared according to the HSG and NHSG routes. The FTIR spectra obtained at $250^{\circ} \mathrm{C}$ are presented in Figure 7. The interesting observation in Figure 7a is the peaks appearing at 2956 and $1144 \mathrm{~cm}^{-1}$ that indicate the $\mathrm{CH}_{2}$ groups and the $\mathrm{C}-\mathrm{Cl}$ bond in ethylene chloride which formed in Step 1 presented in Figure 4. There is also a strong peak at $1756 \mathrm{~cm}^{-1}$, which indicates that acid chlorides may have formed part of the volatiles released at this temperature. It seems as if the ethylene chloride is less volatile than the ethanol formed during the HSG sol-gel reaction with TEOS as precursor [16]. The ethanol probably evaporated during the course of the sol-gel reaction, while the ethylene chloride formed during the NHSG sol-gel reaction with silicon tetrachloride remained trapped in the polymer and only evaporated at much higher temperatures during the TGA analyses of the samples. The larger mass loss observed for the TESPT containing samples prepared according to the NHSG route is clearly due to the evaporation of ethylene chloride and other acid chlorides, as discussed above, together with unreacted TESPT (the additional peaks in Figure $7 \mathrm{~b}$ correspond well with the typical peaks of TESPT, as described earlier). We can therefore confidently state that TESPT did not

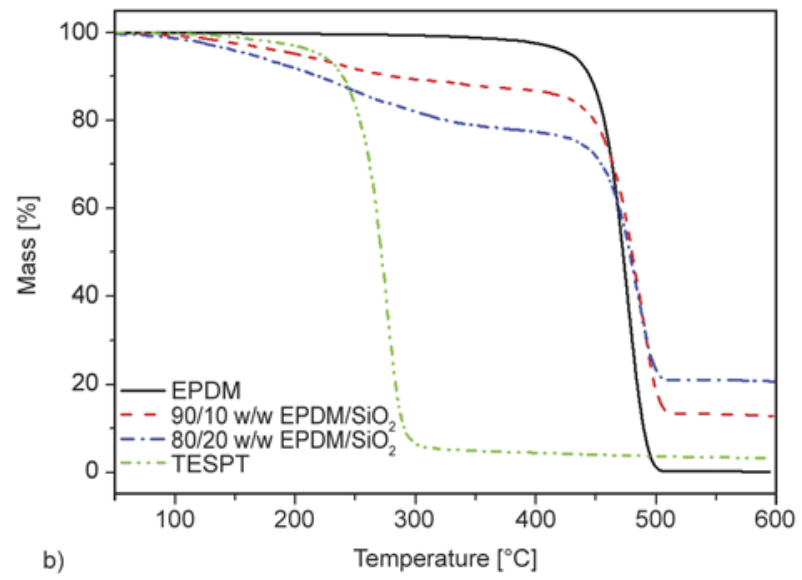

Figure 6. TGA curves for a) EPDM and silica filled EPDM composites and b) EPDM and silica filled EPDM composites in the presence of TESPT 

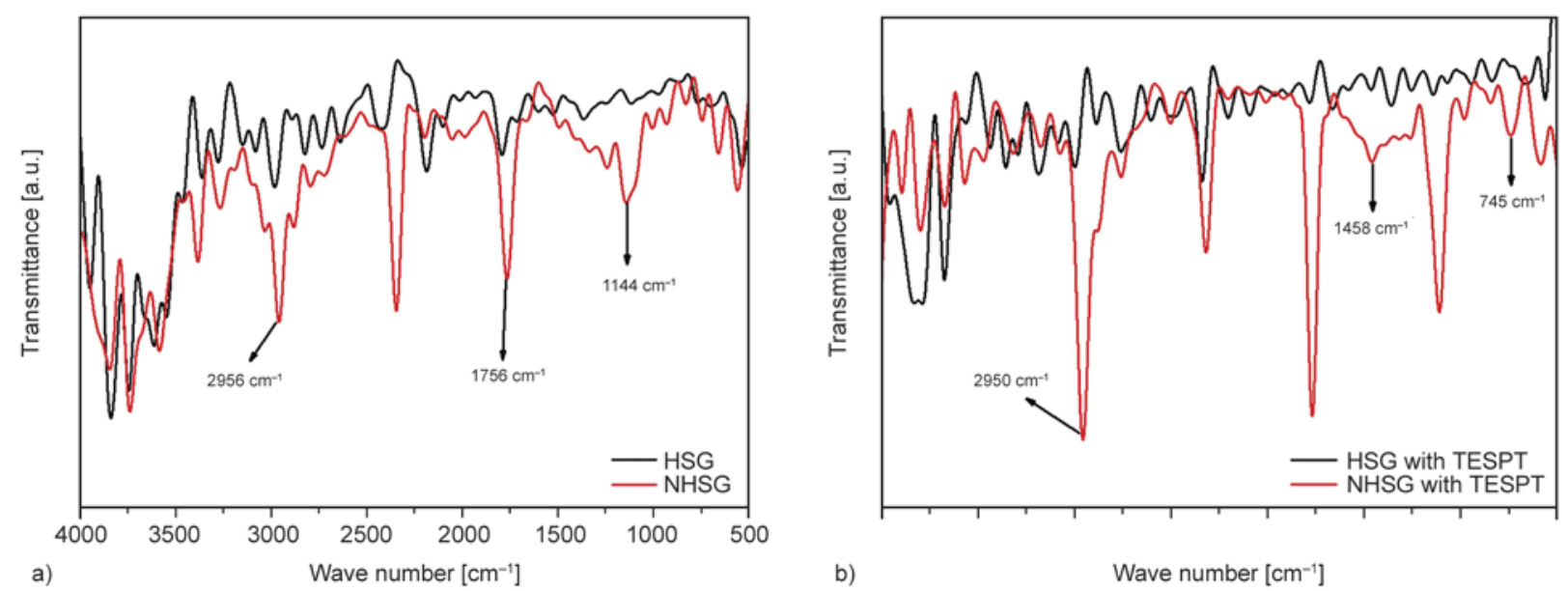

Figure 7. FTIR spectra of $80 / 20 \mathrm{w} / \mathrm{w}$ EPDM $/ \mathrm{SiO}_{2}$ during the thermal degradation in a TGA at a heating rate of $10^{\circ} \mathrm{C} \cdot \mathrm{min}^{-1}$ taken at $250^{\circ} \mathrm{C}$ for NHSG and HSG (a) without TESPT and (b) with TESPT

take part in the sol-gel reaction according to the NHSG route with $\mathrm{SiCl}_{4}$ as precursor. It probably went to the interface between the polymer matrix and the silica nanoparticles, and in the process improved the interaction between EPDM and the silica nanoparticles, but not to the same extent as in the HSG process as will be shown later. At higher temperatures the TESPT then evaporated with the ethylene chloride and other acid chlorides.

The onset of thermal degradation looks very similar for all the investigated samples, and the temperatures at maximum degradation rate $\left(T_{\max }\right)$ are also very similar within experimental error. However, the actual rate of degradation is lower for the silicacontaining samples (slopes of second degradation step less steep, Figure 6). The decrease in the rate of degradation is more pronounced for the composites prepared in the presence of TESPT (Figure 6b). The most probable explanation is that the well dispersed silica particles found for samples prepared in the

Table 2. Summary of TGA results of EPDM and EPDM/ $\mathrm{SiO}_{2}$ composites

\begin{tabular}{|c|c|c|c|c|}
\hline Samples & $\begin{array}{c}\mathbf{M}_{300^{\circ} \mathrm{C}} \\
{[\%]}\end{array}$ & $\begin{array}{l}\mathbf{T}_{\max } \\
{\left[{ }^{\circ} \mathbf{C}\right]}\end{array}$ & $\begin{array}{c}\text { Char } \\
\text { content } \\
{[\%]}\end{array}$ & $\% \mathrm{SiO}_{2}$ \\
\hline EPDM & $99.4 \pm 0.04$ & & 0 & 0 \\
\hline \multicolumn{5}{|c|}{ Unmodified composites } \\
\hline $90 / 10 \mathrm{w} / \mathrm{w} \mathrm{EPDM} / \mathrm{SiO}_{2}$ & $92.4 \pm 0.5$ & $480 \pm 1.4$ & $12.9 \pm 0.6$ & $12.9 \pm 0.6$ \\
\hline $80 / 20 \mathrm{w} / \mathrm{w} \mathrm{EPDM} / \mathrm{SiO}_{2}$ & $91.2 \pm 0.3$ & $476 \pm 2.1$ & $22.6 \pm 0.5$ & $22.6 \pm 0.8$ \\
\hline \multicolumn{5}{|c|}{$\begin{array}{c}\text { TESPT modified composites } \\
\end{array}$} \\
\hline TESPT & $6.5 \pm 0.0$ & $277 \pm 1.4$ & $3.3 \pm 0.0$ & - \\
\hline 90/10 w/w EPDM/ $/ \mathrm{SiO}_{2}$ & $89.3 \pm 0.1$ & $481 \pm 4.9$ & $13.7 \pm 1.1$ & $12.8 \pm 0.6$ \\
\hline $80 / 20 \mathrm{w} / \mathrm{w} \mathrm{EPDM} / \mathrm{SiO}_{2}$ & $81.8 \pm 0.5$ & $482 \pm 7.8$ & $22.0 \pm 1.6$ & $21.9 \pm 1.6$ \\
\hline
\end{tabular}

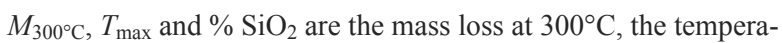
ture at maximum degradation rate, and the silica content after normalization taking into account the char content of TESPT presence of TESPT, reduced the polymer chain mobility and retarded the diffusion of volatile products from the sample.

Table 2 shows that the char content at $600^{\circ} \mathrm{C}$ increases with increasing silica content for the composites prepared in the absence and presence of TESPT. The values are slightly higher than what is theoretically expected, and an FTIR analysis of the char (Figure 8) shows the presence of carbon $(\mathrm{C}-\mathrm{O}$ bending at $1615 \mathrm{~cm}^{-1}$ ). This could explain the higher than expected char content. The other observed peaks are the $\mathrm{Si}-\mathrm{O}-\mathrm{Si}$ stretching and $\mathrm{Si}-\mathrm{O}-\mathrm{C}$ bending at 1055 and $802 \mathrm{~cm}^{-1}$ respectively. The composites prepared in the absence and presence of TESPT show char spectra with similar peaks.

The Young's modulus as function of volume fraction of neat EPDM and its silica filled composites are shown in Figure 9 together with its predicted Nielsen theoretical model fitting [11-13, 24, 25]. The values for Young's modulus, stress and elonga-

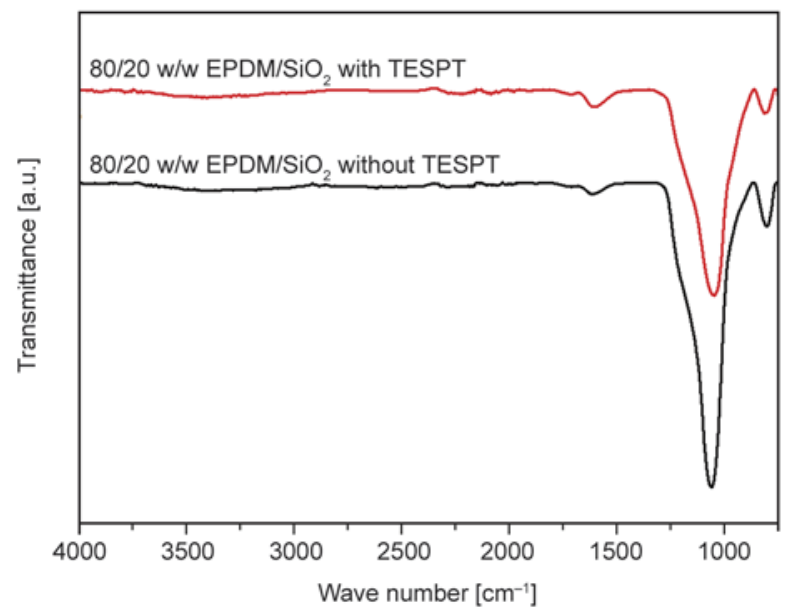

Figure 8. FTIR spectra of the char taken at $600^{\circ} \mathrm{C}$ of two of the investigated composites 
tion at break are summarized in Table 3. For composite materials consisting of spherical particles in the matrix, the Nielsen equation has the form given in Equations (8) and (9):

$$
E=E_{1}\left[\frac{1+A B \varphi_{2}}{1-B \psi \varphi_{2}}\right]
$$

$$
B=\frac{\frac{E_{2}}{E_{1}}-1}{\frac{E_{2}}{E_{1}}+A}
$$

where $E, E_{2}$ and $E_{1}$ are the modulus values of the composite, filler and matrix respectively, and $\varphi_{2}$ is the volume fraction of the filler. The theoretical modulus used for the silica particles was $E_{2}=70 \mathrm{GPa}$ [26]. The factor $\psi$ takes into account the values of $\varphi_{\mathrm{m}}$ of the dispersed phase and it is given by Equation (10):

$\psi=1+\left[\left(\frac{1-\varphi_{\mathrm{m}}}{\varphi_{\mathrm{m}}^{2}}\right) \varphi_{2}\right]$

where $\varphi_{\mathrm{m}}$ is the maximum packing fraction. The constant $B$ takes into account the relative moduli of the filler and matrix phases, and its value is 1.0 for very large $E_{2} / E_{1}$ ratios (the values for $E_{2}$ and $E_{1}$ are $70 \mathrm{GPa}$ and $2.0 \mathrm{MPa}$, respectively, and therefore we could confidently use a value of 1.0). The constant $A$ is related to the Einstein coefficient given by Equation (11) and is determined by the morphology of the system. For strong aggregates, the value of $A$ can become quite large while $\varphi_{\mathrm{m}}$ of the dispersed phase will decrease.

$A=k_{\mathrm{E}}-1$

Figure 9 represents the Young's modulus of all the investigated samples, together with Nielsen's model fittings. The values of the $A$ and $\varphi_{\mathrm{m}}$ used to predict the relationship between the experimental and theoretical moduli were 2.0 and 0.35 respectively for the composites prepared in the absence of TESPT. For the composites prepared in the presence of TESPT, the values of $A$ and $\varphi_{\mathrm{m}}$ were 3.5 and 0.2 . The in situ generation of silica particles by a nonhydrolytic sol-gel route obviously reduced the silica particle size and improve its dispersion in EPDM compared to our previous work using the hydrolytic sol-gel route $[16,17]$. The non-hydrolytic route seems to overcome the typical problems related to

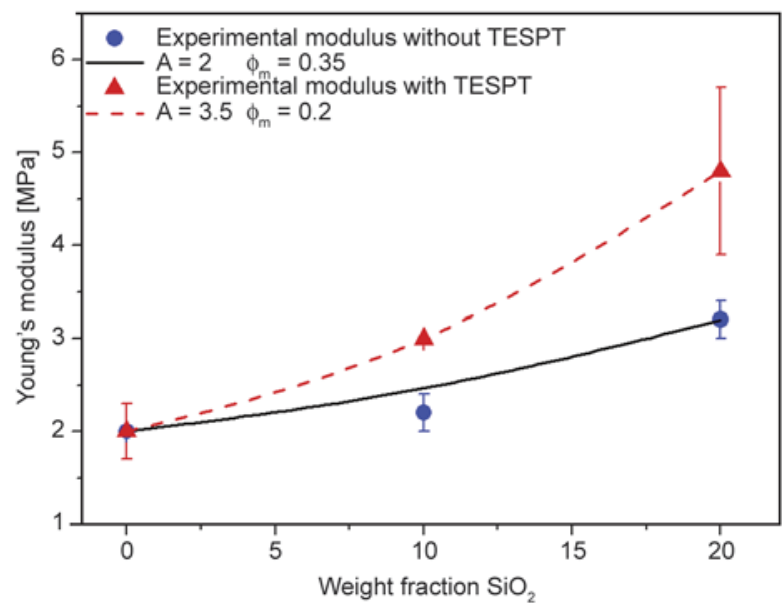

Figure 9. Young's modulus as a function of weight fraction of $\mathrm{SiO}_{2}$ in $\mathrm{EPDM} / \mathrm{SiO}_{2}$ composites $(\boldsymbol{\Delta})$ with TESPT and $(\bullet)$ without TESPT: experimental modulus and Nielsen's model fittings

hydrolytic route, in which the low miscibility of the sol-gel aqueous system limits the dispersion and distribution of the filler in the matrix. The low value of $\varphi_{\mathrm{m}}$ indicates the presence of agglomerated silica particles, but the aggregates are small enough for the value of $A$ to be fairly small. The composites prepared in the presence of TESPT shows a better Nielsen's model fit and higher Young's modulus values than the composites prepared in absence of TESPT. This is in line with the smaller particles and better dispersion observed in the TEM images in Figure 2. Smaller particles and better dispersion will improve the matrix-filler interaction and increase the rubber reinforcement, giving rise to higher tensile modulus values.

The stress and elongation at break values observably increase with increasing silica content for all the $\mathrm{EPDM} / \mathrm{SiO}_{2}$ composites compared to those of the neat EPDM (Table 3). This indicates good reinforcement and is the result of improved adhesion between the filler and the matrix giving rise to effective stress transfer. For $10 \mathrm{wt} \%$ of filler the stress and elongation at break values increased, but for $20 \mathrm{wt} \%$ filler these values decreased, but they are still higher than that of pure EPDM. The reason for this observation is the agglomeration of the silica particles in the $20 \mathrm{wt} \%$ filled composite. The composites prepared in the presence of TESPT have significantly higher stress at break, but lower elongation at break, values than the comparable composites prepared in the absence of TESPT. The most probable explanation for the lower elongation at break for the samples prepared in the presence of TESPT is 
Table 3. Summary of tensile results of EPDM and EPDM/ $\mathrm{SiO}_{2}$ composites

\begin{tabular}{|l|c|c|c|}
\hline \multicolumn{1}{|c|}{ Samples } & $\begin{array}{c}\mathbf{E} \\
{[\mathbf{M P a}]}\end{array}$ & $\begin{array}{c}\mathbf{\sigma}_{\mathbf{b}} \\
{[\mathbf{M P a}]}\end{array}$ & $\begin{array}{c}\boldsymbol{\varepsilon}_{\mathbf{b}} \\
{[\%]}\end{array}$ \\
\hline EPDM & $2.0 \pm 0.3$ & $1.6 \pm 0.3$ & $589 \pm 43$ \\
\hline \multicolumn{4}{|c|}{ Unmodified composites } \\
\hline 90/10 W/w EPDM/ $\mathrm{SiO}_{2}$ & $2.2 \pm 0.2$ & $4.9 \pm 2.1$ & $2863 \pm 101$ \\
\hline $80 / 20 \mathrm{~W} / \mathrm{W} \mathrm{EPDM} / \mathrm{SiO}_{2}$ & $3.2 \pm 0.2$ & $3.4 \pm 0.3$ & $1865 \pm 35$ \\
\hline \multicolumn{4}{|c|}{ TESPT modified composites } \\
\hline 90/10 W/w EPDM $/ \mathrm{SiO}_{2}$ & $3.0 \pm 0.0$ & $10.0 \pm 1.6$ & $1570 \pm 14$ \\
\hline $80 / 20 \mathrm{~W} / \mathrm{W} \mathrm{EPDM} / \mathrm{SiO}_{2}$ & $4.8 \pm 0.9$ & $4.4 \pm 2.1$ & $963 \pm 10$ \\
\hline
\end{tabular}

$E, \sigma_{\mathrm{b}}$ and $\varepsilon_{\mathrm{b}}$, are the modulus, stress at break and elongation at break

Table 4. Percentage change in stress and elongation at break with change in reaction route and with addition of TESPT

\begin{tabular}{|l|c|c|}
\hline $\begin{array}{c}\text { Changes in the reaction route } \\
\left(\mathbf{8 0 / 2 0} \mathbf{w} / \mathbf{w} \mathbf{~ E P D M} / \mathbf{S i O}_{\mathbf{2}} \mathbf{)}\right.\end{array}$ & $\begin{array}{c}\boldsymbol{\sigma}_{\mathbf{b}} \\
{[\mathbf{M P a}]}\end{array}$ & $\begin{array}{c}\boldsymbol{\varepsilon}_{\mathbf{b}} \\
{[\mathbf{\%}]}\end{array}$ \\
\hline $\begin{array}{l}\mathrm{HSG} \rightarrow \\
\mathrm{NHSG} \text { in the absence of TESPT }\end{array}$ & $2.9 \rightarrow 3.4$ & $956 \rightarrow 1865$ \\
\hline $\begin{array}{l}\text { HSG } \rightarrow \\
\text { NHSG in the presence of TESPT }\end{array}$ & $3.7 \rightarrow 4.4$ & $1060 \rightarrow 963$ \\
\hline Presence of TESPT for HSG & 3.7 & 1060 \\
\hline Presence of TESPT for NHSG & 4.4 & 963 \\
\hline
\end{tabular}

that TESPT probably settled on the interface between the silica particles and EPDM and did not form part of the network. Table 4 shows the differences between the stress and elongation at break values of the samples prepared according to the HSG and NHSG routes, and in the absence and presence of TESPT. The change in the reaction route from HSG to NSHG shows increased $\sigma_{\mathrm{b}}$ and $\varepsilon_{\mathrm{b}}$ values as a result of smaller particles and better particle-matrix interactions. However, when TESPT was present, the same change in reaction route only improved the stress at break, but reduced the elongation at break. The reason for this is the fact that during the HSG

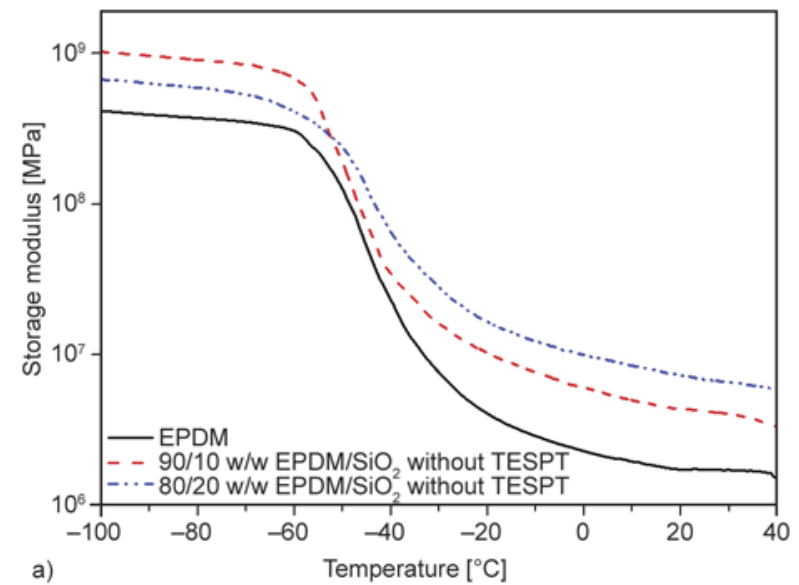

route the TESPT takes part in the sol-gel reaction and becomes part of the crosslinked network, while during the NHSG route it does not take part in the sol-gel reaction and only sits on the EPDM-silica interface.

Values obtained from dynamic mechanical analysis (DMA) are summarized in Table 5. The filler effectiveness (Factor C) in the rubber matrix can be evaluated from the values of the storage modulus obtained in the glassy and rubbery regions by using Equation (12) [27]:

Factor $\mathrm{C}=\frac{\left(\frac{E_{\mathrm{g}}^{\prime}}{E_{\mathrm{r}}^{\prime}}\right) \text { composites }}{\left(\frac{E_{\mathrm{g}}^{\prime}}{E_{\mathrm{r}}^{\prime}}\right) \text { matrix }}$

where, $E_{\mathrm{g}}^{\prime}$ and $E_{\mathrm{r}}^{\prime}$ are the storage moduli determined in the glassy and rubbery regions, respectively. The state of filler dispersion in the rubber matrix was determined by calculation of the damping reduction (DR) from the damping values obtained from the normalized $\tan \delta$ peaks $\left((\tan \delta)_{\mathrm{EPDM}}\right.$ and

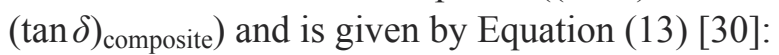

$$
\mathrm{DR}=\frac{(\tan \delta)_{\mathrm{EPDM}}-(\tan \delta)_{\text {composite }}}{(\tan \delta)_{\mathrm{EPDM}}} \cdot 100
$$

The DMA results of EPDM and its nanocomposites are shown in Figures 9 and 10. The glass transition temperature, the $\tan \delta$ value at the glass transition peak maximum, the storage modulus at -80 and $20^{\circ} \mathrm{C}$, Factor $\mathrm{C}$ and the damping reduction values are summarized in Table 5. The storage modulus values in the glassy region increase with increasing silica content (see $E^{\prime}{ }_{\mathrm{T}}=-80^{\circ} \mathrm{C}$ values in Table 5). There

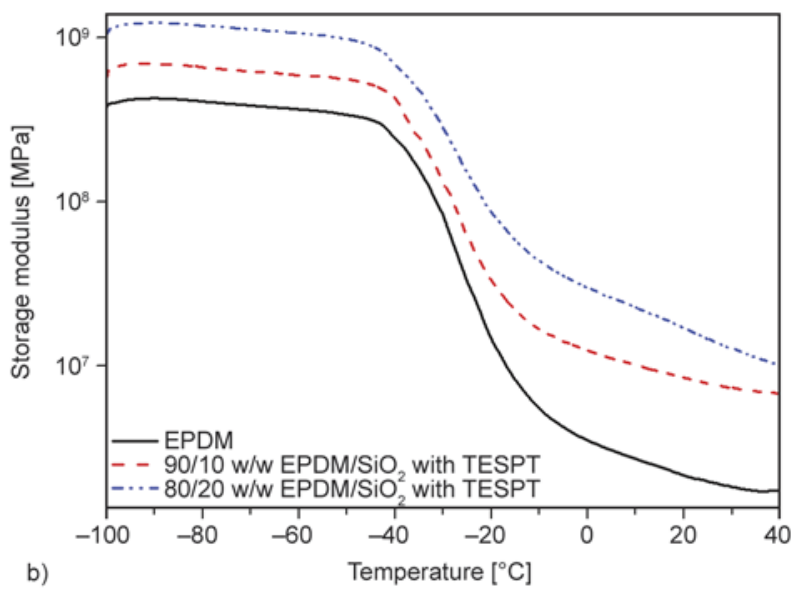

Figure 10. DMA storage modulus curves of EPDM and composites (a) without TESPT and (b) with TESPT 
is also a significant increase in the storage modulus with increasing silica content in the rubbery region (see $E^{\prime}{ }_{\mathrm{T}}=20^{\circ} \mathrm{C}$ values in Table 5 and shown in Figure 10). These modulus values depend on (i) the degree of crosslinking of the rubber, (ii) the content of the rigid dispersed phase, and (iii) the sizes of the filler particles. All these factors will contribute to an increase in the modulus. As can be seen from Table 1, the degree of crosslinking decreased with increasing silica content. However, the presence of the rigid dispersed silica particles and their interaction with EPDM reduced the chain mobility and increased the stiffness of the rubber to such an extent that the effect of the reduced crosslinking was not observable. The increase in agglomeration at higher silica content may also have contributed to the increase in modulus. Furthermore, the modulus values of the composites prepared in the presence of TESPT are significantly higher than those of the comparable composites prepared in the absence of TESPT and this is also observed in Figure 10. This is in line with the already discussed Young's modulus values. The $(\tan \delta)_{\max }$ values in (Figure 11 and Table 5) clearly decrease with increasing silica content for the composites prepared in the absence and presence of TESPT, and they are lower for the samples prepared in the presence of TESPT. This is attributed to good adhesion between the filler and the matrix, which resulted in a restriction in the rubber chain mobility in the composites. The damping reduction ( $\mathrm{DR}^{\mathrm{Norm}}$ ) values, which increased with both increasing silica content and with TESPT treatment, confirm the stronger interaction of EPDM with smaller and well dispersed silica particles which led to a reduction in the polymer chain mobility. However, the glass transition temperature $\left(T_{\mathrm{g}}\right)$ decreased for the $10 \mathrm{wt} \%$ silica-containing samples (Table 5), but again increased for the $20 \mathrm{wt} \%$ silica-containing samples. Reduced crosslinking should decrease the value of $T_{\mathrm{g}}$, while the presence of the silica particles and their interaction with EPDM should reduce the mobility of the rubber chains and increase the value of $T_{\mathrm{g}}$. In the case of the $10 \mathrm{wt} \%$ silica containing samples the reduced crosslinking seems to have a dominant effect, while the effect of chain immobilization by the silica particles is more dominant in the case of the $20 \mathrm{wt} \%$ silica containing samples.

Table 5. Summary of DMA results of EPDM and EPDM/ $\mathrm{SiO}_{2}$ composites with and without TESPT

\begin{tabular}{|c|c|c|c|c|c|c|}
\hline $\begin{array}{c}\text { Samples } \\
(\mathbf{w} / \mathbf{w})\end{array}$ & $\begin{array}{l}\mathrm{E}_{-80^{\circ} \mathrm{C}}^{\prime} \\
{[\mathrm{MPa}]}\end{array}$ & $\begin{array}{l}\mathbf{E}_{20^{\circ} \mathrm{C}} \\
{[\mathrm{MPa}]}\end{array}$ & $(\tan \delta)_{\max }$ & $\begin{array}{c}\mathbf{T}_{\mathbf{g}} \\
{\left[{ }^{\circ} \mathbf{C}\right]}\end{array}$ & $\begin{array}{c}\text { DR }^{\text {Norm }} \\
{[\%]}\end{array}$ & Factor $\mathbf{C}$ \\
\hline EPDM & 4.1 & 1.7 & 0.5188 & -41.0 & - & 1.00 \\
\hline \multicolumn{7}{|c|}{ Unmodified composites } \\
\hline 90/10 EPDM/SiO ${ }_{2}$ & 9.1 & 4.2 & 0.5197 & -46.7 & -0.17 & 1.21 \\
\hline $80 / 20 \mathrm{EPDM} / \mathrm{SiO}_{2}$ & 5.9 & 6.8 & 0.4405 & -42.1 & 15.10 & 0.38 \\
\hline \multicolumn{7}{|c|}{ TESPT modified composites } \\
\hline 90/10 EPDM/SiO ${ }_{2}$ & 6.6 & 6.9 & 0.4378 & -44.3 & 15.60 & 0.45 \\
\hline $80 / 20 \mathrm{EPDM} / \mathrm{SiO}_{2}$ & 11.8 & 9.9 & 0.3958 & -42.5 & 23.70 & 0.57 \\
\hline
\end{tabular}

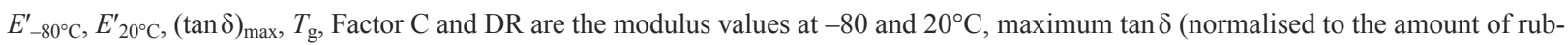
ber in the nanocomposites), glass transition temperature, filler effectiveness and the damping reduction (calculated from $\left.(\tan \delta)_{\max }\right)$
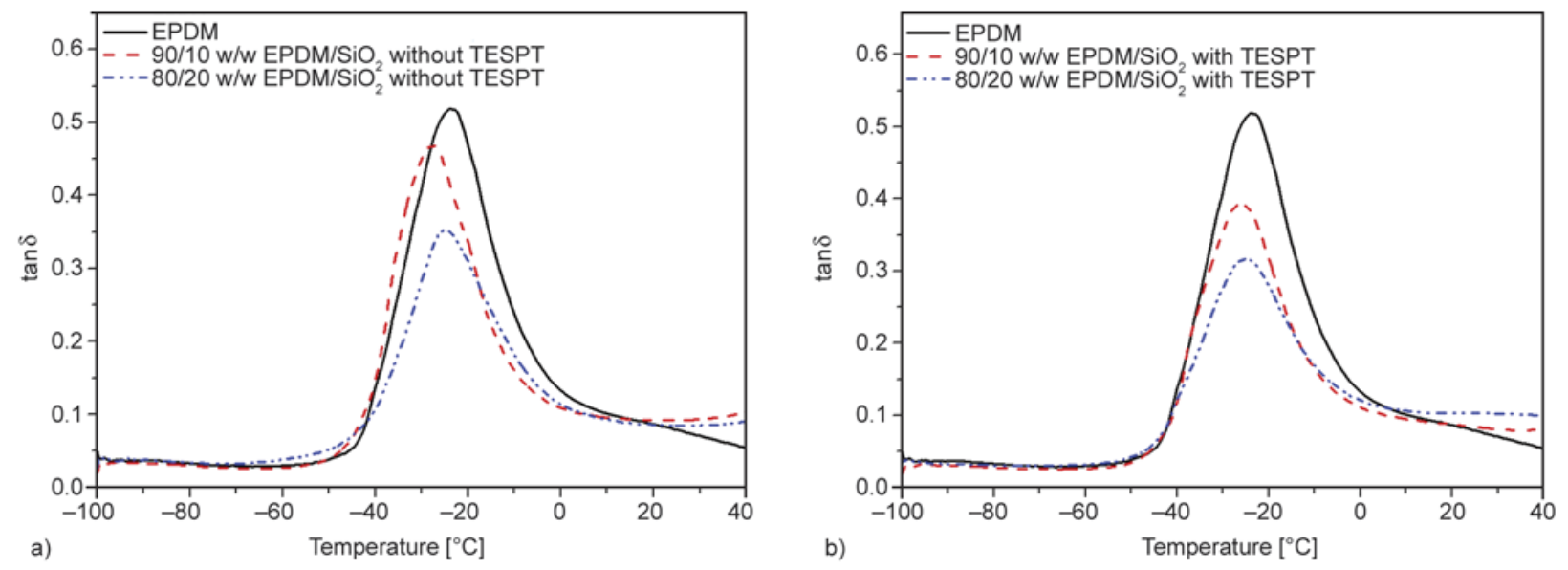

Figure 11. DMA damping factor curves of EPDM and composites (a) without TESPT and (b) with TESPT 
Table 6. Storage modulus at $40^{\circ} \mathrm{C}$ of $\mathrm{EPDM} / \mathrm{SiO}_{2}$ nanocomposites prepared according to the HSG and NHSG routes in the absence and presence of TESPT

\begin{tabular}{|c|c|}
\hline \multicolumn{2}{|c|}{$\mathbf{E}_{\mathrm{T}}^{\prime}=40^{\circ} \mathrm{C}[\mathrm{MPa}]$} \\
\hline \multicolumn{2}{|c|}{ Hydrolytic sol-gel (HSG) route without TESPT } \\
\hline 90/10 w/w EPDM/SiO 2 & $80 / 20 \mathrm{w} / \mathrm{w} \mathrm{EPDM} / \mathrm{SiO}_{2}$ \\
\hline 6.7 & 12.3 \\
\hline \multicolumn{2}{|c|}{ Hydrolytic sol-gel (HSG) route with TESPT } \\
\hline 90/10 w/w EPDM/SiO ${ }_{2}$ & $80 / 20 \mathrm{w} / \mathrm{w} \mathrm{EPDM} / \mathrm{SiO}_{2}$ \\
\hline 8.2 & 8.8 \\
\hline \multicolumn{2}{|c|}{ Non-hydrolytic sol-gel (NHSG) route without TESPT } \\
\hline 90/10 w/w EPDM/ $/ \mathrm{SiO}_{2}$ & $80 / 20 \mathrm{w} / \mathrm{w} \mathrm{EPDM} / \mathrm{SiO}_{2}$ \\
\hline 4.2 & 6.8 \\
\hline \multicolumn{2}{|c|}{ Non-hydrolytic sol-gel (NHSG) route with TESPT } \\
\hline 90/10 w/w EPDM/ $/ \mathrm{SiO}_{2}$ & $80 / 20 \mathrm{w} / \mathrm{w} \mathrm{EPDM} / \mathrm{SiO}_{2}$ \\
\hline 6.7 & 9.9 \\
\hline
\end{tabular}

$E^{\prime}{ }_{40^{\circ} \mathrm{C}}$, storage modulus value at $40^{\circ} \mathrm{C}$

Table 6 shows the storage modulus values in the rubbery region at $40^{\circ} \mathrm{C}$ for the $\mathrm{EPDM} / \mathrm{SiO}_{2}$ composites prepared according to the HSG and NHSG routes in the absence and presence of TESPT. Generally, comparable composites prepared according to the HSG route show higher storage modulus values than the composites prepared according to the NHSG route. The reason for this is probably that the TESPT formed part of the network structure for the samples prepared according to the HSG route, while it sat on the EPDM-silica interface for the samples prepared according to the NHSG route, to some extent acting as a plasticizer.

The filler effectiveness (Factor C) can be used to indicate the composite reinforcing capacity. By definition an unfilled rubber matrix has a Factor $\mathrm{C}$ equal to 1 , and a Factor $\mathrm{C}$ lower than 1 indicates a mechanical stiffening effect as well as a thermal stability contribution of the used filler [27]. The values in Table 5 show that the silica particles improved the stiffness of EPDM. However, the 90/10 w/w EPDM/ $\mathrm{SiO}_{2}$ composite shows values that are not in line with the rest of the values. This is the result of the high storage modulus values obtained at temperatures below the glass transition temperature. This result was found to be reproducible, and therefore it is not possible to offer an explanation at this point in time.

\section{Conclusions}

Non-hydrolytic sol-gel synthesis of EPDM-silica composites prepared in the absence and presence of a coupling agent was investigated. The TEM results showed that in the absence of TESPT the silica par- ticles were homogeneously and fairly well dispersed, but with clear evidence of particle agglomeration and much larger agglomerates were visible at high silica content $(20 \mathrm{wt} \%)$. The introduction of TESPT reduced the particle-particle interaction, and gave rise to much reduced agglomeration and observably better dispersion. The presence of silica particles inhibited the crosslinking density of the vulcanized EPDM matrix for all the composites prepared in the absence and presence of TESPT. The reduced crosslinking density of the composites prepared in the absence of TESPT was caused by reduced amounts of DCP available to initiate crosslinking, because the DCP was partially utilised in the grafting of silanol groups onto the rubber chains. In the case of the composites prepared in the presence of TESPT, the decline was due to the coupling agent that probably settled on the interface between the silica particles and EPDM and did not form part of the network. This caused enough free volume between the chains to accommodate the toluene molecules during swelling, and resulted in an increase in the swelling ratio.

The thermal stability of the EPDM/ $/ \mathrm{SiO}_{2}$ composites showed two mass loss steps for all the composites. The mass loss in the range $100-400^{\circ} \mathrm{C}$ was caused by the evaporation of ethylene chloride and other acid chlorides present in the composites, as well as the evaporation of TESPT that settled on the interface between the silica particles and EPDM for composites prepared in the presence of TESPT.

The Nielsen fitting of the Young's modulus indicated smaller and better dispersed filler particles for the NSHG route, and this further improved when the preparation was done in the presence of TESPT. Improved stress at break was observed as a result of improved EPDM-silica interactions that led to better stress transfer. However, the elongation at break was lower for the samples prepared in the presence of TESPT, probably because TESPT settled on the interface between the silica particles and EPDM and did not form part of the network. The DMA results supported the observations and conclusions from the other techniques.

In summary, the NHSG route generally gave rise to smaller and better dispersed filler particles than the HSG route, and this was reflected in the investigated thermal and mechanical properties of the composites. However, the presence of TESPT during the sol-gel preparation had a much smaller influ- 
ence in the NHSG route. This is probably because TESPT did not take part in the sol-gel reaction and only settled on the interface between EPDM and the silica particles, as was established from a thermal degradation analysis of the samples.

\section{Acknowledgements}

The National Research Foundation in South Africa and the Italian Ministry of Foreign Affairs (Italy-South Africa bilateral collaboration project) are acknowledged for financial support of the project.

\section{References}

[1] Morselli D., Bondioli F., Fiorini M., Messori M.: Poly (methyl methacrylate)- $\mathrm{TiO}_{2}$ nanocomposites obtained by non-hydrolytic sol-gel synthesis: The innovative tert-butyl alcohol route. Journal of Materials Science, 47, 7003-7012 (2012).

DOI: $10.1007 / \mathrm{s} 10853-012-6651-4$

[2] Morselli D., Messori M., Bondioli F.: Poly(methyl methacrylate) $-\mathrm{TiO}_{2}$ nanocomposite obtained by nonhydrolytic sol-gel synthesis. Journal of Materials Science, 46, 6609-6617 (2011).

DOI: $10.1007 / \mathrm{s} 10853-011-5610-9$

[3] Morselli D., Bondioli F., Sangermano M., Messori M.: Photo-cured epoxy networks reinforced with $\mathrm{TiO}_{2}$ insitu generated by means of non-hydrolytic sol-gel process. Polymer, 53, 283-290 (2012).

DOI: $10.1016 /$ j.polymer.2011.12.006

[4] Mutin P. H., Vioux A.: Nonhydrolytic processing of oxide-based materials: Simple routes to control homogeneity, morphology, and nanostructure. Chemistry of Materials, 21, 582-596 (2009).

DOI: $10.1021 / \mathrm{cm} 802348 \mathrm{c}$

[5] Debecker D. P., Mutin P. H.: Non-hydrolytic sol-gel routes to heterogeneous catalysts. Chemical Society Reviews, 41, 3624-3650 (2012).

DOI: $10.1039 / \mathrm{C} 2 \mathrm{CS} 15330 \mathrm{~K}$

[6] Lafond V., Mutin P. H., Vioux A.: Non-hydrolytic solgel routes based on alkyl halide elimination: Toward better mixed oxide catalysts and new supports: Application to the preparation of a $\mathrm{SiO}_{2}-\mathrm{TiO}_{2}$ epoxidation catalyst. Journal of Molecular Catalysis A: Chemical, 182-183, 81-88 (2002).

DOI: 10.1016/S1381-1169(01)00487-3

[7] Niederberger M.: Nonaqueous sol-gel routes to metal oxide nanoparticles. Accounts of Chemical Research, 40, 793-800 (2007).

DOI: $10.1021 / \operatorname{ar} 600035 \mathrm{e}$

[8] Lind C., Gates S. D., Pedoussaut N. M., Baiz T. I.: Novel materials through non-hydrolytic sol-gel processing: Negative thermal expansion oxides and beyond. Materials, 3, 2567-2587 (2010).

DOI: $10.3390 / \mathrm{ma3} 042567$
[9] Arnal P., Corriu R. J. P., Leclercq D., Mutin P. H., Vioux A.: A solution chemistry study of nonhydrolytic sol-gel routes to titania. Chemistry of Materials, 9, 694-698 (1997).

DOI: $10.1021 / \mathrm{cm} 960337 \mathrm{t}$

[10] Hay J. N., Raval H. M.: Synthesis of organic-inorganic hybrids via the non-hydrolytic sol-gel process. Chemistry of Materials, 13, 3396-3403 (2001).

DOI: $10.1021 / \mathrm{cm} 011024 \mathrm{n}$

[11] Wu Y-P., Jia Q-X., Yu D-S., Zhang L-Q.: Modeling Young's modulus of rubber-clay nanocomposites using composite theories. Polymer Testing, 23, 903-909 (2004).

DOI: $10.1016 /$ j.polymertesting.2004.05.004

[12] Jayasree T. K., Predeep P.: Effect of fillers on mechanical properties of dynamically crosslinked styrene butadiene rubber/high density polyethylene blends. Journal of Elastomers and Plastics, 40, 127-146 (2008).

DOI: $10.1177 / 0095244307083865$

[13] Ahmed S., Jones F. R.: A review of particulate reinforcement theories for polymer composites. Journal of Materials Science, 25, 4933-4942 (1990). DOI: 10.1007/BF00580110

[14] Nielsen L. E.: Morphology and the elastic modulus of block polymers and polyblends. Rheologica Acta, 13, 86-92 (1974). DOI: $10.1007 / \mathrm{BF} 01526889$

[15] Nielsen L. E., Landel R. F.: Mechanical properties of polymers and composites. Marcel Dekker, New York (1994).

[16] Mokhothu T. H., Luyt A. S., Morselli D., Bondioli F., Messori M.: Influence of in situ-generated silica nanoparticles on EPDM morphology, thermal, thermomechanical, and mechanical properties. Polymer Composites, in press (2014).

DOI: $10.1002 / p c .23002$

[17] Mokhothu T. H., Luyt A. S., Messori M.: Reinforcement of EPDM rubber with in situ generated silica particles in the presence of a coupling agent via a sol-gel route. Polymer Testing, 33, 97-106 (2014).

DOI: $10.1016 /$ j.polymertesting.2013.11.009

[18] Messori M., Bignotti F., De Santis R., Taurino R.: Modification of isoprene rubber by in situ silica generation. Polymer International, 58, 880-887 (2009). DOI: $10.1002 /$ pi.2606

[19] Ikeda Y., Kemeda Y.: Preparation of 'green' composites by the sol-gel process: In situ silica filled natural rubber. Journal of Sol-Gel Science and Technology, 31, 137-142 (2004). DOI: 10.1023/B:JSST.0000047975.48812.1b

[20] Prasertsri S., Tattanasom N.: Mechanical and damping properties of silica/natural rubber composites prepared from latex system. Polymer Testing, 30, 515-526 (2011).

DOI: $\underline{10.1016 / j . p o l y m e r t e s t i n g .2011 .04 .001 ~}$ 
[21] Wang H., Zhong W., Xu P., Du Q.: Polyimide/silica/ titania nanohybrids via a novel non-hydrolytic sol-gel route. Composites Part A: Applied Science and Manufacturing, 36, 909-914 (2005).

DOI: $10.1016 /$ j.compositesa.2004.12.008

[22] Zhu D., Van Ooij W. J.: Structural characterization of bis-[triethoxysilylpropyl]tetrasulfide and bis-[trimethoxysilylpropyl]amine silanes by Fourier-transform infrared spectroscopy and electrochemical impedance spectroscopy. Journal of Adhesion Science and Technology, 16, 1235-1260 (2002).

DOI: $10.1163 / 156856102320256873$

[23] Motaung T. E., Luyt A. S., Thomas S.: Morphology and properties of NR/EPDM rubber blends filled with small amounts of titania nanoparticles. Polymer Composites, 32, 1289-1296 (2011).

DOI: $10.1002 /$ pc. 21150
[24] Barra G. M. O., Crespo J. S., Bertolino J. R., Soldi V., Pires A. T. N.: Maleic anhydride grafting on EPDM: Qualitative and quantitative determination. Journal of the Brazilian Chemical Society, 10, 31-34 (1999). DOI: 10.1590/S0103-50531999000100006

[25] Hussain A. I., Tawfic M. L., Khalil A. A., Awad T. E.: High performance emulsified EPDM grafted with vinyl acetate as compatibilizer for EPDM with polar rubber. Nature and Science, 8, 348-357 (2010).

[26] Hsieh T. H., Kinloch A. J., Masania K., Lee J. S., Taylor A. C., Sprenger S.: The toughness of epoxy polymers and fibre composites modified with rubber microparticles and silica nanoparticles. Journal of Materials Science, 45, 1193-1210 (2010).

DOI: $10.1007 / \mathrm{s} 10853-009-4064-9$

[27] Gregorova A., Machovsky M., Wimmer R.: Viscoelastic properties of mineral-filled poly(lactic acid) composites. International Journal of Polymer Science, 2012, 252981/1-252981/6 (2012).

DOI: $10.1155 / 2012 / 252981$ 